\title{
The collaboration between Int J Life Cycle Assess and J LCA Jpn
}

\author{
Abstracts of research articles published in "The Journal of Life Cycle Assessment, \\ Japan" (J LCA Jpn), Vol. 5, No. 3, 2009
}

\author{
Yasunari Matsuno $\cdot$ Yasushi Kondo
}

Received: 8 April 2010 /Accepted: 8 April 2010 /Published online: 27 April 2010

(C) Springer-Verlag 2010

\section{Preamble}

The Institute of Life Cycle $A$ ssessment $J$ apan (ILCAJ) was established in October 2004. The goal of ILCAJ is to promote academic activities related to life-cycle thinking and to share expert knowledge with colleagues from wideranging backgrounds. Professor Ryoichi Yamamoto, University of Tokyo, has taken responsibility as Chairman of ILCAJ.

In April 2005, ILCAJ has successfully established its publication organ (in Japanese), The Journal of Life Cycle Assessment Japan (J LCA Jpn). The issues appear every 3 months. J LCA Jpn publishes peer-reviewed research articles, commentaries and discussions, (technical) reports, lecture notes, and presentations of research groups in Japan, along with others. In Int J Life Cycle Assess 12(6):348 350 , we were happy to announce the collaboration with $\mathrm{J}$ LCA Jpn for the purpose of exchanging knowledge, new insights, experiences, and information across different languages.

The Corner : JLCA Jpn aims to be a bridge between the LCA community of Japan and that of the whole world. All

Responsible editors: Yasunari Matsuno and Yasushi Kondo

Y. Matsuno $(\bowtie)$

Department of Materials Engineering,

Graduate School of Engineering, University of Tokyo,

7-3-1 Hongo, Bunkyo-ku,

113-8656 Tokyo, Japan

e-mail: matsuno@material.t.u-tokyo.ac.jp

Y. Kondo

Faculty of Political Science and Economics, Waseda University,

1-6-1 Nishi-waseda Shinjuku-ku,

169-8050 Tokyo, Japan

e-mail: ykondo@waseda.jp abstracts of research articles published in J LCA Jpn, as well as commentaries and discussions, will appear in Int J Life Cycle Assess, Corner: JLCA Jpn, in order to introduce Japanese activities to our readers. In addition, some selected research papers from J LCA Jpn will be submitted to Int J Life Cycle Assess for publication following peer review. We hope that this collaboration will stimulate the global exchange of information through professional pathways. The following abstracts were published in J LCA Jpn Vol. 5, No. 3.

Professor Hiroshi Mizutani, Nihon University has become the Editor-in-Chief of J LCA Jpn since January 2009.

\section{Research articles}

2.1 Effects of environmental education program with LCA educational software: a mechanism to induce proenvironmental behavior

\section{Yoshie Hirayama $\cdot$ Kota Nakajima $\cdot$ Hiroki Hondo}

Graduate School of Environment and Information Sciences Yokohama National University, 79-7, Tokiwadai, Hodogaya, Yokohama 240-8501, Japan

Objective Education is one of the important and effective tactics to promote "sustainable consumption." In a highly developed consumer society, it is required that consumers notice and understand environmental impacts of their consumption and life styles. In order to induce individual sense of responsibility for environmental issues and motivation for environment-friendly life style, it is important to make consumers understand the "link" between their life styles and global environmental problems such as global warming. Thus, the use of the concept of "life cycle 
thinking" in environmental education is expected to be effective. The authors have developed a novel environmental education program using LCA software "Global warming even in your bag?!" that runs on a personal computer and is easy to handle. This program can make learners recognize how much life cycle $\mathrm{CO}_{2}$ was emitted from their own daily lives as well as how effectively they can reduce it by changing their behavior. The objective of the present study is to analyze psychological mechanism which forms the intention of pro-environmental behavior of students after implementing the developed program in junior high and high schools.

Results and discussion The program was implemented in four school classes. Questionnaire surveys were conducted after each class to investigate the realization of the "link," the change in psychological factors (e.g. sense of responsibility) and the change in behavioral intention towards environment conservation. The survey data indicate that the students strongly recognized the "link," and increased sense of responsibility, perceived effectiveness, and behavioral intention etc. Analyses of the survey data suggest that the recognition of the "link" between daily life and $\mathrm{CO}_{2}$ emission based on life cycle thinking seems to increase sense of responsibility and perceived effectiveness, and then the two factors seem to induce the formation of behavioral intention. Conclusions The use of "life cycle thinking" as a core concept in environmental education can help induce individual sense of responsibility for global warming as well as perceived effectiveness of behavioral change. In addition, the use of the LCA software also is effective to induce behavioral change because it can supply learners with the tailored information on current life cycle $\mathrm{CO}_{2}$ emission and allows for the virtual experiences to reduce life cycle $\mathrm{CO}_{2}$ emission.

2.2 Effect of environmental education using the "Carbon Footprint" of cabbage from the Choshi area, Chiba Prefecture

\section{Takao Ando}

Chiba Institute of Science, 3 Shiomi-cho, Choshi, Chiba 288-0025, Japan

Objective This study developed a new environmental education program calculating the Carbon Footprint (CFP) of cabbage grown in Choshi city, Chiba prefecture. CFP is expected to be an environmental communication tool used to visualize the amount of $\mathrm{CO}_{2}$ emission by human activities. CFP can assist consumers in achieving sustainable consumption if they are provided information on the amount of $\mathrm{CO}_{2}$ emitted through the whole life cycle of products. While is important to establish a low carbon society, it is difficult to comprehend how our daily life is linked to global environ- mental problems through $\mathrm{CO}_{2}$ emission. This disconnected situation is called the "missing link". The presented educational program aimed to recover the "missing links". Method This program was applied to 33 junior high school students in Choshi city. This program consists of a 40-min lecture, a 60-min cooking experiment, and a 50-min group work presentation and discussion. The lecture is a brief overview of the cabbage life cycle and the calculation method of CFP. The life cycle of cabbage is defined as the following eight stages, cultivation, yield, storage, transportation, selling, refrigeration, cooking, and disposal stages. CFP was calculated by the addition of the amount of $\mathrm{CO}_{2}$ emission in each life cycle stage. The students choose from a standard set of transportation, refrigeration, cooking, and disposal stages scenarios, and consider ways of improving their scenarios. In the cooking experiment, students measure the amount of $\mathrm{CO}_{2}$ emission for various cooking methods, e.g. LPG range, induction heater, electric heater, and microwave. The calculated results of CFP are presented and discussed along with CFP reduction methods. The effects of this program are evaluated by a questionnaire and an analysis of student's descriptions.

Results and discussion The results of the group discussion and presentation showed that the students became more conscious of the $\mathrm{CO}_{2}$ emission from their daily life and realized the connection between the $\mathrm{CO}_{2}$ emissions and the global environmental problems. Analyses on the data from the questionnaires indicated that this program was effective in making students recognize the "link" between their daily life and $\mathrm{CO}_{2}$ emissions. An analysis of students' descriptions showed that an awareness of "perceived effectiveness" and "a sense of responsibility" resulted in enhancing behavioral intension of environmental action.

Conclusions The use of CFP in environmental education programs was considered effective in addressing the recovery of the "missing link" between global environmental problems based on $\mathrm{CO}_{2}$ emissions and our daily life, as well as modifying environmental action. It was important for students to be "facilitators" in promoting discussions appropriately. Adjusting system boundaries appropriately, this program could be highly effective for various education levels from elementary school to college.

2.3 Development of a new program for environmental education based on mobile phone technologies

\section{Asami Narita $\cdot$ Hiroki Inoue $\cdot$ Shinya Matsumoto $\cdot$ Eiko Nakamura}

Yokohama National University, 79-2 Tokiwadai, Hodogaya-ku, Yokohama 240-8501, Japan

Background and goal For establishing a sustainable society, one of the important parameters in considering the effects 
of environmental education (EE) is to recognize our material world with literacy on science. Our group has developed a new program for EE related with this. Our program should provide an opportunity for students to recognize that our life strongly influences on the environment with respect to large consumption of materials and energies. The goal of our program is their understanding of this picture with acquisition of science literacy related with industrial products. Outline of the program: The program is composed of several parts according to four learning steps, awareness, knowledge, recognition, and understanding. This program was carefully designed from the standpoint of a life cycle of products. Mobile phone, which is becoming an ordinary product in our daily life, plays a key role in our program. It is used as a material for introduction, and its three components, plastics, semiconductors, and batteries were determined as the particular educational subjects related with science literacy. The unit for these subjects includes both a lecture based part and a group work. A factory tour was also incorporated as an extramural learning opportunity. The students reconsider the life cycle of a mobile phone and their daily lives at the conclusion of the program.

Results and discussion The whole program was successfully designed and the corresponding educational materials have been developed. Among three units for the particular part, the details of the materials on plastics are described with the introduction and conclusion parts on mobile phone in this report. The developed program was put in practice at several high schools in Tokyo and Kanagawa prefectures from 2007 to 2008. A questionnaire survey was employed in order to evaluate the educational effects of the program by using multiple-choice and free-description methods. The result indicated that almost all the students had been aware of the link between their daily lives and the environment with acquisition of new knowledge and recognition on a mobile phone and plastics.Conclusions and perspectives A new EE program focusing on material world and science literacy has been developed using mobile phone as an example. The intended educational effects of the program including the plastic unit were confirmed in its practice at several high schools. Development of the materials for the other two units, semi-conductors and batteries, are now in progress and their details will be reported elsewhere with their educational effects.

2.4 Life cycle evaluation of decolorization system using electrolysis for colored piggery wastewater

Hotaka Kai ${ }^{1}$ - Yasuhiro Ishibashi ${ }^{2}$ - Isao Kawaguchi ${ }^{3}$. Masahumi Yoshida $^{4}$. Takahiro Nakamichi ${ }^{5}$. Shinichi Kamohara $^{2} \cdot$ Hiroki Ohwaki $^{6} \cdot$ Koji Arizono $^{7}$ - Takehiro Takemasa $^{8}$
${ }^{1}$ Graduate School of Science and Technology, Nagasaki University (currently, College of Analytical Chemistry, Japan), 1-14, Bunkyo-machi, Nagasaki-city, Nagasaki 852-8521, Japan

${ }^{2}$ Faculty of Human Environment, Nagasaki Institute of Applied Science, 3-1, Syuku-machi, Nagasaki-city, Nagasaki 852-0121, Japan

${ }^{3}$ Osaka carbon steel Co. Ltd. 813-1, Hariokitamachi, Sasebo-city, Nagasaki 859-3454, Japan

${ }^{4}$ Environmental Conservation Section of Nagasaki City Office, 2-22, Sakuramachi, Nagasaki-city, Nagasaki 8508685, Japan

${ }^{5}$ Graduate School of Engineering, Nagasaki Institute of Applied Science, 3-1, Syuku-machi, Nagasaki-city, Nagasaki 852-0121, Japan

${ }^{6}$ Industrial Technology Center of Nagasaki, 2-1303-8 Ikeda, Omura-city, Nagasaki 856-0026, Japan

${ }^{7}$ Faculty of Environmental and Symbiotic Science, Prefectural University of Kumamoto, 3-1-100 Tsukide, Kumamoto-city, Kumamoto 862-8502, Japan

${ }^{8}$ Graduate School of Science and Technology, Nagasaki University, 1-14, Bunkyo-machi, Nagasaki-city, Nagasaki 852-8521, Japan

Objective Livestock wastewater from pig farmer is generally treated by activated sludge process. However, it turns to brownish color (colored piggery wastewater). Before discharging colored piggery wastewater, it is necessary to decolorize. Colored piggery wastewater can be decolorized by ozone treatment or ultraviolet treatment. However, they need a lot of electricity, they will have a lot of $\mathrm{CO}_{2}$ emission and high environmental loads. Authors researched and developed the decolorization system by electrolysis. From the results of pilot test, authors evaluated that it can be utilized for decolorization. In this study, authors carried out Life Cycle Assessment (LCA) for electrolysis, ozone, and $\mathrm{NaClO}$ decolorization system. In LCA, at first, making input and output data such as resources for machine and chemicals and electricity for each decolorization system clearer and inventory analysis were carried out. However, there is no LCA report for ozone generation system, resources for ozone generation system was unknown. Authors referred $\mathrm{CO}_{2}, \mathrm{NOx}$, and $\mathrm{SOx}$ generation from 3 EID as output data for inventory analysis. From the result of inventory analysis, authors evaluated the generation of $\mathrm{CO}_{2}, \mathrm{NOx}$, and SOx. And then Life Cycle Impact Assessment was carried out using by Life-cycle Impactassessment Method based on End point modeling (LIME). Results and discussion From the result of inventory analysis, $\mathrm{CO}_{2}$ emission of electrolyzed decolorization, ozone decolorization and $\mathrm{NaClO}$ decolorization that decolorize $10 \mathrm{t}$ colored piggery wastewater in a day were indicated $3.37 \times 10^{1} \mathrm{~kg} \mathrm{CO}, 5.26 \times 10^{1} \mathrm{~kg} \mathrm{CO}_{2}$ and $3.51 \times$ 
$10^{1} \mathrm{~kg} \mathrm{CO}$, respectively. NOx emission was indicated $1.88 \times 10^{-2} \mathrm{~kg} \mathrm{NO}_{x}, 3.42 \times 10^{-2} \mathrm{~kg} \mathrm{NO}_{x}$, and $7.07 \times 10^{-2} \mathrm{~kg}$ $\mathrm{NO}_{x}$, respectively. SOx emission was indicated $6.36 \times 10^{-3}$ $\mathrm{kg} \mathrm{SO}_{x}, 1.31 \times 10^{-2} \mathrm{~kg} \mathrm{SO}_{x}$, and $1.20 \times 10^{-2} \mathrm{~kg} \mathrm{SO}_{x}$, respectively. The influence of electrolyzed decolorization system was the smallest in the result of Human Health; however, it was the largest in Social Asset, Biodiversity and Primary Production. It became clear that the influence of global warming and urban area air pollution on electrolyzed decolorization was the smallest. However, electrolyzed decolorization needs many titanium electrodes. From the results of LCIA, the influence of resource consumption in electrolyzed decolorization was largest. The result of Single Index, ozone decolorization system showed the smallest value. In case of setting up electrolyzed decolorization system instead of ozone decolorization system in $45 \%$ farmer, it indicated that a lot of $\mathrm{CO}_{2}, \mathrm{NOx}$, and $\mathrm{SOx}$ emission would be controlled.

Conclusions This study carried out life cycle evaluation for electrolyzed decolorization system, ozone decolorization system and $\mathrm{NaClO}$ decolorization system. It has examined that $\mathrm{CO}_{2}, \mathrm{NOx}$, and SOx emissions in electrolyzed decolorization system were the smallest; however the influence of resource consumption was largest. 